\title{
'Would you eat cultured meat?': Consumers' reactions and attitude formation in Belgium, Portugal and the United Kingdom
}

\author{
Wim Verbeke ${ }^{\mathrm{a}, *}$, Afrodita Marcu $^{\text {b }}$, Pieter Rutsaert ${ }^{\mathrm{a}, \mathrm{c}}$, Rui Gaspar ${ }^{\mathrm{d}, \mathrm{e}}$, Beate Seibt ${ }^{\mathrm{d}, \mathrm{f}}$, \\ Dave Fletcher ${ }^{\mathrm{g}}$, Julie Barnett ${ }^{\mathrm{h}}$ \\ a Ghent University, Department of Agricultural Economics, Coupure links 653, B-9000 Gent, Belgium \\ b University of Surrey, School of Psychology, Guildford Surrey GU2 7XH, United Kingdom \\ c International Rice Research Institute (IRRI), Los Baños, Laguna, Philippines \\ d Instituto Universitário de Lisboa (ISCTE-IUL), Cis-IUL, 1649-026 Lisboa, Portugal \\ e Universidade de Évora, Departamento de Psicologia, Centro de Investigação em Educação e Psicologia (CIEP), Escola de Ciências Sociais, 7005-345 Évora, Portugal \\ ${ }^{\mathrm{f}}$ University of Oslo, Department of Psychology, 0373 Oslo, Norway \\ ${ }^{g}$ White October, OX4 1LF Oxford, United Kingdom \\ ${ }^{\text {h }}$ University of Bath, Department of Psychology, BA2 7AY Bath, United Kingdom
}

\section{A R T I C L E I N F O}

\section{Article history:}

Received 4 June 2014

Received in revised form 16 October 2014

Accepted 28 November 2014

Available online 9 December 2014

\section{Keywords:}

Attitude

Consumer

Cultured

In-vitro

Meat

Synthetic

\begin{abstract}
A B S T R A C T
Cultured meat has evolved from an idea and concept into a reality with the August 2013 cultured hamburger tasting in London. Still, how consumers conceive cultured meat is largely an open question. This study addresses consumers' reactions and attitude formation towards cultured meat through analyzing focus group discussions and online deliberations with 179 meat consumers from Belgium, Portugal and the United Kingdom. Initial reactions when learning about cultured meat were underpinned by feelings of disgust and considerations of unnaturalness. Consumers saw few direct personal benefits but they were more open to perceiving global societal benefits relating to the environment and global food security. Both personal and societal risks were framed in terms of uncertainties about safety and health, and possible adverse societal consequences dealing with loss of farming and eating traditions and rural livelihoods. Further reflection pertained to skepticism about 'the inevitable' scientific progress, concern about risk governance and control, and need for regulation and proper labeling.
\end{abstract}

(c) 2014 Elsevier Ltd. All rights reserved.

\section{Introduction}

Meat production and consumption are highly topical but also increasingly controversial consumer issues nowadays. Many consumers in Western countries may already have changed their meat consumption habits during the last decade, or may still intend doing so in the near future (Verbeke, Pérez-Cueto, de Barcellos, Krystallis \& Grunert, 2010; Vanhonacker, Van Loo, Gellynck \& Verbeke, 2013). Possible reasons are the consecutive meat safety crises since the mid-nineties (Verbeke, Pérez-Cueto, de Barcellos, Krystallis \& Grunert, 2010) followed by the more recent debates about the health (McAfee et al., 2010; Pan et al., 2012) and sustainability (Aston, Smith \& Powles, 2012; Austgulen, 2014) consequences of meat production and consumption. In addition, variability of meat quality in general and palatability in particular may have led to consumer dissatisfaction and a gradual shift away from traditional muscle-type meat (Verbeke et al., 2010; Hocquette et al., 2014). While a number of meat substitutes have been

\footnotetext{
* Corresponding author at: Ghent University, Coupure links 653, B-9000 Gent, Belgium. Tel.: + 3292646181 ; fax: + 3292646246

E-mail address: wim.verbeke@ugent.be (W. Verbeke).
}

developed, such as products based on soy protein (with varieties including tofu and seitan) and Quorn ${ }^{\circledR}$, many non-vegetarian consumers tend to avoid such products because they are insufficiently perceived as 'resembling meat' or as providing the same sensory experience as real meat (Hoek et al., 2011). At the same time, the tendency towards lower per capita meat intake in Western countries is forecast to be largely outweighed by an increased demand for animal products and meat in developing countries (Steinfeld et al., 2006). Global trends and the related challenges in terms of feeding and satisfying the growing and increasingly demanding world population have fuelled the search for novel protein sources as possible substitutes for traditional meat.

One of the most intriguing recent examples of novel proteins is meat cultured from stem cells (Post, 2012). Commonly used names for the resulting product, which became a reality with the August 2013 burger-tasting in London, are 'synthetic', 'cultured' (the term used in this paper), 'in vitro', 'artificial', 'laboratory-grown' or 'factory-grown' meat. Hocquette et al. (2013) reviewed the potential of cultured meat relative to traditionally produced meat and identified technical, economic and social constraints, including an uncertain acceptance by consumers, as major limitations. Similarly, Mattick and Allenby (2012) 
have discussed the implications of a potential shift from traditional to cultured meat, while Goodwin and Shoulders (2013) have analyzed print media coverage of cultured meat, revealing that between 2005 and 2011 cultured meat has been discussed in terms of benefits, history, process, time, livestock production problems, and skepticism, but mostly by sources qualified as proponents of cultured meat. Post (2014), the leading scientist behind the recent development of cultured meat, has outlined the technological challenges ahead for cultured meat, and has also pointed out that public perceptions and consumer reactions remain largely unknown and uninvestigated.

Several recent examples of novel agro-food technologies, such as biotechnology and nanotechnology have illustrated that European consumers may not embrace food technologies as enthusiastically as hoped for at the time when the technologies were developed and adopted (Verbeke, 2011). Furthermore, the importance of involving the public and consumers early in the development process has been stressed as a determinant of future technology acceptance (Frewer et al., 2011) and successful food product development (Grunert, Verbeke, Kügler, Saeed, \& Scholderer, 2011). This holds in particular for the meat sector where "new product development is a major competitive parameter [...] for producers competing on a mature and developed market", and where besides the fact that most new products fail on the market, "differentiated new products adapted to the needs of specific customer segments might give protection against price competition, replace products that face declining sales at the end of their lifecycles, and can contribute to creating customer satisfaction and loyalty" (Grunert et al., 2011, p. 251). Hence, consumer insight is crucial for those directly involved in the development of cultured meat (products) as well as for the larger group of those expected to face competition from this novel product in the future.

Thus far very few studies have focused on consumer reactions and their likelihood of accepting or rejecting (the idea of eating) cultured meat. A survey conducted in the Netherlands in February 2013 with a representative sample of 1296 participants indicated that $79 \%$ had never heard of cultured meat, while $14 \%$ had heard of it and claimed to know what it is about (Flycatcher, 2013). After explaining the technique and its possible advantages and disadvantages, $63 \%$ supported the idea of producing cultured meat and $52 \%$ claimed to be willing to try cultured meat. An Internet poll organized by The Guardian in the United Kingdom (UK) right after the public unveiling of the cultured hamburger in August 2013 revealed that two thirds of the UK participants expressed interest to try cultured meat (The Guardian, 2013).

A few recent consumer studies set out to delve deeper into the possible reactions, objections, motives and perceived barriers of consumers in relation to the concept of cultured meat. Hopkins and Dacey's (2008) overview of potential objections to cultured meat included worry about unknown dangers or applications of the technology beyond culturing animal cell tissue for human consumption, lack of 'realness' and naturalness, disgust at the idea of eating cultured meat, alongside moral objections related to the technology and its application. Verbeke, Sans, and Van Loo (in press) have addressed the possible criteria that can be expected to shape consumer acceptance or rejection of cultured meat and the possible consumer concerns that may arise when facing this new technology and novel food product. Their study conducted with Belgian consumers largely corroborates the results of the previously mentioned polls in the Netherlands and the UK in that only a minority of consumers rejected outright the idea of trying cultured meat. Their study suggests that the majority of consumers have hesitant attitudes (selecting 'maybe') when asked whether they would be willing to try cultured meat in the future. The fact that many consumers hesitate between expressing either acceptance or rejection of cultured meat encourages the search for a better understanding of how consumers make sense of this new technology and its end products.

Therefore, given the paucity of evidence around consumer acceptance or rejection of cultured meat, this study investigates consumers' reactions to the concept of cultured meat in several European countries prior to the first public unveiling of the cultured meat burger in August 2013. Drawing on social representations theory, the study first analyzed how the public make sense of 'synthetic meat' and how people might transform scientific concepts like 'culturing meat from muscle stem cells' into common-sense (Marcu, Gaspar, Rutsaert, Seibt, Fletcher, Verbeke, \& Barnett, 2014). This analysis revealed that people use different sensemaking strategies to discuss cultured meat: among others, people ask questions, wonder about the societal implications, anchor cultured meat to more familiar objects (like biotechnologies), use metaphors (mostly borrowed from science-fiction) and consider how cultured meat might eventually lead to a change in meat consumption practices. The analysis presented in the present paper delves deeper into the content of the participants' reactions and their attitudes towards cultured meat.

\section{Materials and methods}

\subsection{Overall study framework and design}

This study focuses on the affective and cognitive components of attitudes to articulate consumers' feelings, beliefs, and predispositions as either favorable or unfavorable towards the concept of cultured meat. The affective component, i.e. consumers' feelings and emotional reactions to an object (Batra \& Kazmi, 2008), may be one of like or dislike without a specific cognitive basis for these feelings (Zajonc, 1980), as seen for example in the case of Westerner consumers' aversion towards the eating of insects as an alternative source of protein (Looy, Dunkel \& Wood, 2014; Verbeke, 2015). Initial reactions may be followed by more cognitive processes including the formation of beliefs through connecting an object, its attributes, the possible benefits and risks it entails, and finally, further reflections about the wider context in which the object presents itself. This basic attitude formation outline (Fig. 1) is used as the framework for structuring, presenting and discussing the consumers' reactions to the concept of cultured meat, and in turn to explore how cultured meat, as a product, may be accepted or rejected in the future. Our research questions were: would consumers express acceptance or rejection of cultured meat? Would their attitudes towards cultured meat be underpinned mostly by affective or by cognitive reactions? And what beliefs might drive their acceptance or rejection? Each of these issues is explored in turn.

Consumer views on cultured meat were elicited in two separate but related studies, which were both run in Belgium, Portugal, and the UK as part of the EU FP7-funded research project FoodRisC. One study consisted of exploratory focus group discussions, while the other study was online and involved the use of a web-based deliberation tool, VIZZATA ${ }^{\mathrm{TM}}$, which had been developed to provide an online environment where participants could engage in an asynchronous dialogue with the research team (Barnett et al., 2008). The online tool presented the participants with pieces of information, termed content testers, which consisted of images, text, and a video. The participants were prompted online to leave questions and comments in relation to the study material, and could indicate to which of these they wanted responses from the research team (see Marcu et al., 2014, for further description of the VIZZATA ${ }^{\mathrm{TM}}$ tool). The stimulus material in both the online and focus group studies consisted of the same seven content testers pertaining to various possible risks and benefits of red meat. While in the online study, the content testers were presented sequentially on screen, in the focus groups, the content testers were printed out on separate sheets of paper which the participants were asked to read one at a time. One of these content testers was a two-minute long YouTube video on cultured meat (Appendix A). This video was presented in English in all three countries, both in the online study and in the focus groups (in the latter, with the help of a video projector and loud speakers). The video, entitled 'Would you eat synthetic meat?', had been produced by the Royal Institution of Australia as part of the series 'Three technologies which may change the way we live'. The Belgian and Portuguese focus groups and online participants were sufficiently 


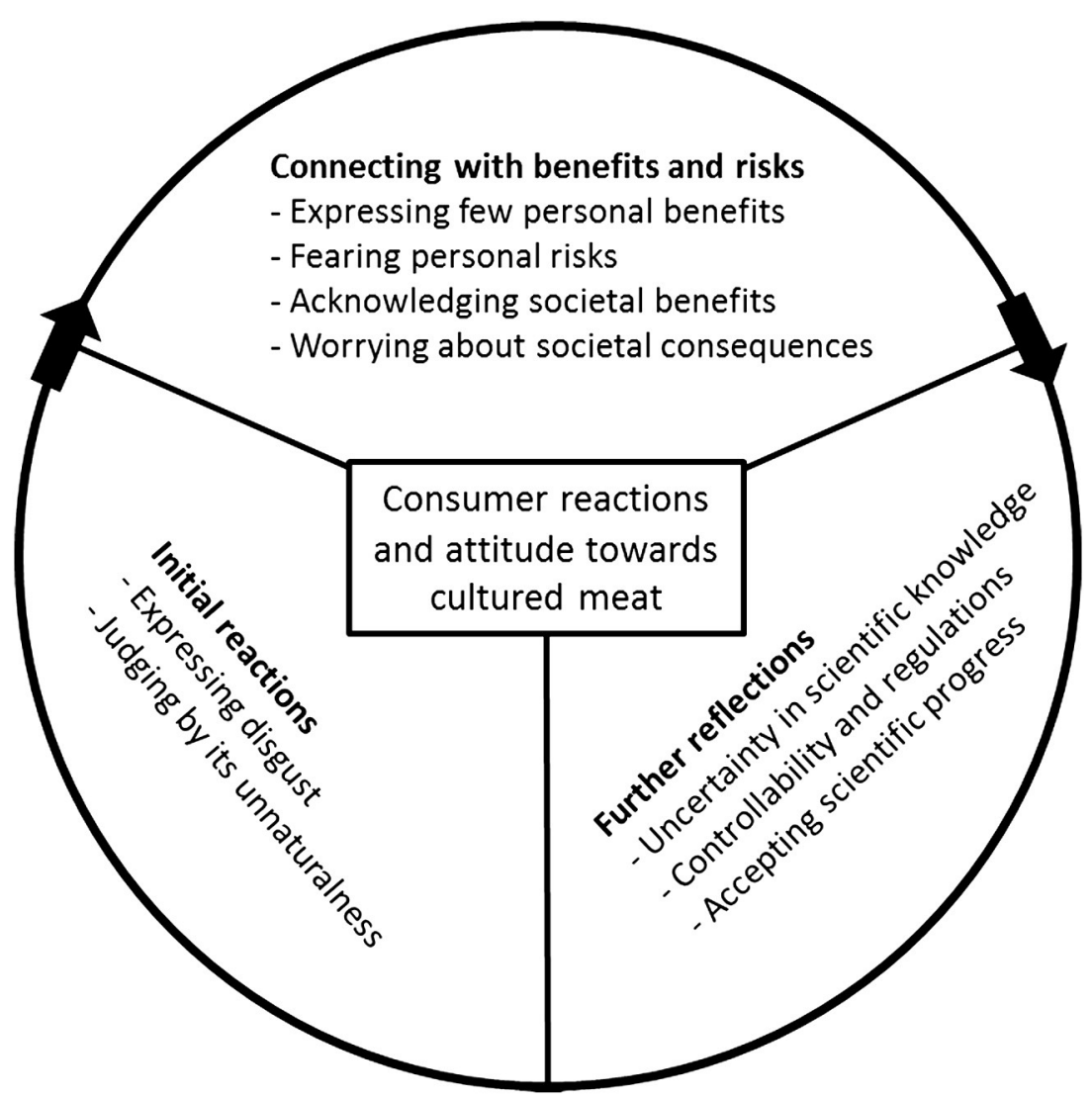

Fig. 1. Framework for thematic analysis: consumer reactions and attitude towards cultured meat.

fluent in English to be able to follow the video in English without needing additional language related explanations or translations.

\subsection{Participants and procedure}

A total of 109 meat consumers for focus group discussions in October 2012, and 174 online participants in July 2012, were recruited via market research companies from Belgium, Portugal, and the UK. In accordance with methodological guidelines around focus group research (e.g. Morgan, 1996), six focus groups were conducted in each country, with six or seven participants per focus group, leading to a total of 58 females and 51 males, age range $=21$ to 65 years. Although the number of participants was relatively low in each focus group, this is fully in line with qualitative research which stipulates that focus groups should comprise six to 10 participants. At the same time, smaller groups are appropriate when the given topic is likely to be emotionally charged or when the researchers want to obtain a high level of participant involvement (Morgan, 1996). Seventy of the 174 online participants, 34 females and 36 males, age range $=18$ to 60 years, left comments and/or questions in relation to the cultured meat video. The most prevalent age group was 4150 years $(32.1 \%)$ in the focus group sample, and $31-35$ years $(24.3 \%)$ in the online sample. All participants were non-vegetarians, and most consumed red meat 2-3 times a week. This share amounted to $52.3 \%$ of the

Table 1

The participants' gender across the three countries (frequency).

\begin{tabular}{|c|c|c|c|c|c|c|}
\hline \multirow[t]{2}{*}{ Study } & \multicolumn{2}{|c|}{ Belgium $(n=59)$} & \multicolumn{2}{|c|}{ Portugal $(n=60)$} & \multicolumn{2}{|c|}{$\mathrm{UK}(n=60)$} \\
\hline & Females & Males & Females & Males & Females & Males \\
\hline Focus groups & 20 & 16 & 20 & 17 & 18 & 18 \\
\hline Online study ${ }^{*}$ & 12 & 11 & 10 & 13 & 14 & 10 \\
\hline
\end{tabular}

* We include in this paper only the online participants who left at least one comment or posed at least one question in relation to the cultured meat video. focus group participants, and $41.4 \%$ of the online sample. Table 1 presents the breakdown of gender per study and per country.

In the online study, the participants were prompted to leave comments and questions on the content tester page pertaining to the video. The Portuguese and Belgian participants left their contributions in their own language, which were subsequently translated into English for analysis. The seventy online participants left a total of 24 questions and 64 comments, with similar numbers of contributors in each country: Belgium $(n=23)$, Portugal $(n=23)$, and UK $(n=24)$. The online participants' questions and comments were categorized in terms of content, and responses to their questions were provided within 10 days.

In the focus group study, the participants were encouraged to raise comments and queries in relation to the video, although they were informed from the start that the researchers would not be able to provide complete answers during the group discussion but that we would debrief them at the end. To mirror the online study conditions for accurate comparison, the moderation in the focus groups was kept to a minimum and no additional information was provided when asked so by the participants. This information was only provided after the end of the focus groups sessions, upon the participants' request. Overall, the main difference between the focus groups and the online study was the presence of other participants, whose questions and comments, as well as emotional reactions, led to more heated debates and to group polarization, issues that have been addressed in a separate paper (see Marcu et al., 2014). Overall, the content of the participants' reactions was the same in the focus groups as in the online studies (see Marcu et al., 2014).

\subsection{Qualitative analysis}

All analyses were conducted in English and were supported by the use of the qualitative data analysis software NVivo9 (QSR International Pty Ltd.). Thematic analysis was employed, with themes representing patterns of meaning in the data (Braun \& Clarke, 2006; Joffe \& Yardley, 
2004) as outlined in the study framework. Data were categorized into sub-themes, and similar sub-themes were grouped into master themes. The analysis was inductive as it was data-driven and no specific theoretical framework was employed to interpret the data, although in our coding we aimed to address our research questions and thus focused on the most relevant aspects of the data. The facts that our study participants were all meat-eaters and that their responses were situated within the discussion of the various risks and benefits of red meat in general were taken into account. In this paper, no distinction is made between online and focus group participants as their reactions were largely similar, something that has been addressed elsewhere (Marcu et al., 2014). Findings are presented and discussed using verbatim statements (or quotes) obtained from the study participants and grouped in thematic boxes (Boxes 1,2, and 3). Next to each participant quote, country $(\mathrm{BE}=$ Belgium, $\mathrm{PT}=$ Portugal, and UK $=$ United Kingdom), the online ID number or focus group (FG) session number, respectively, gender ( $\mathrm{F}=$ female, $\mathrm{M}=$ male), and age or age group of the participant are indicated.

\section{Results}

\subsection{Consumers' initial reactions towards cultured meat}

This theme summarizes how the participants reacted when first hearing about cultured meat. None of them had heard or seen anything similar before and a few expressed shock at the idea of producing cultured meat. Participants' initial reactions can be categorized as 'visceral' as they were driven by emotions as much as by reasoning.

\subsubsection{Expressing disgust}

Often, the first reaction that participants expressed was an emotional one, mostly disgust but also fear at the thought of eating cultured meat which they regarded as "scary", "frightening", and "weird". Some participants acknowledged that their "first impression was negative", while others could not even bear to watch the video because they found the idea of cultured meat "ridiculous" and "completely unnatural" (Box 1A, B).

Disgust was a shared emotion among the participants, and in some instances it set the tone of the ensuing discussion around cultured meat, leading to a negative evaluation and closing off potential considerations of its benefits. In line with some research around the impact of disgust on reasoning, according to which disgust can increase the severity of moral judgments (Schnall, Haidt, Clore, \& Jordan, 2008), it could be argued that the initial emotional reaction triggered by the video made the participants judge cultured meat in a relatively negative light in the first instance. This is exemplified by the initial reactions taken from a dialogue of participants in one of the focus groups in the UK (Box 1C-G).

The disgust expressed by the participants could be argued to stem from the perceived transgression of what should have been a natural food product: meat. In line with research around the notion of 'natural' (e.g. Rozin, 2005), the participants' revulsion indicated that cultured meat was perceived as an undesirable food not necessarily due to its content or what it is, but rather due to the process of creating it or how it came about, e.g. Box $1 \mathrm{H}$. The participants were repulsed at the idea that cultured meat was created in a petri dish, something they associated with in-vitro fertilization and creating babies, and also at the idea that the muscle cells needed electrical impulses to grow, something they linked to science-fiction and Frankenstein's monster. Such associations made some participants express particularly strong reactions against cultured meat (Box 1I-K).

\subsubsection{Judging cultured meat by its unnaturalness}

Following initial reactions of disgust, many participants viewed cultured meat to be unnatural and even against nature, and expressed
Box 1

Consumers' initial reactions towards cultured meat.

Expressing disgust

A "This sounds unhealthy and disgusting." (UK Online475, M, $31-35)^{a}$

B "I am not a fan of this, I wouldn't want this ... I have my questions about it." (BE FG1, F, 32)

C "To me: no." (UK FG4, M, 50)

D "I wouldn't like to eat that, no." (UK FG4, F, 65)

E "Synthetic, that just sounds awful." (UK FG4, M, 50)

$F$ "I have only one word for this: disgusting." (UK FG4, F, 21)

G "It's vile, isn't it?" (UK FG4, M, 44)

$\mathrm{H}$ "It's not a question of speeding or forcing a process, it's a system of synthetic creation. Instead of being an animal [it] is a piece of meat that grows somewhere." (PT FG1, M, 40)

I "Maybe we should eat cow in place of creating this freakish thing..." (UK FG6, M, 31)

$\mathrm{J}$ "It does scare me when it becomes something ... because it's still processed..." (UK FG6, F, 33)

K "I would never, personally, I would never put that in my mouth, ever!" (UK FG6, M, 42)

Judging cultured meat by its unnaturalness

$\mathrm{L}$ "I would never want to eat synthetic meat because this is not natural." (BE Online431, F, 25-30)

$M$ "Synthetic meat? I don't like that word 'synthetic'". (UK FG1, $\mathrm{F}, 45)$

N "I associate this to cloning, mutation, bottom-line to genetic manipulation because it's meat production in an abnormal manner. The scientific involvement [with the otherwise natural process of meat production] is not normal." (PT FG6, F, 44)

$\mathrm{O}$ "Food is sensitive, because you don't want everything to come from factories. Like vegetables, you want meat to be natural and that it has grown somewhere." (BE FG2, F, 21)

$P$ "Brilliant research, OK for medical reasons and things, but mocking around with this like cloning, you know, Dolly the sheep, you're mocking around with nature." (UK FG6, F, 33)

Q "It's just the way we ... we have evolved, isn't it? We were meat-eaters, and really, maybe that's where the problem started, when we started being vegetarians, because we have always been meat-eaters" (UK FG2, F, 55)

$\mathrm{R}$ "We do need to eat meat to survive, or take supplements, but, 50 years ago, supplements weren't available. So, again, we're kind of compensating for not doing what's natural to us." (UK FG2, M, 45)

$S$ "We are eating meat from prehistory and now we might replace it with something else, something not natural. And we don't know what the effect on our health could be." (BE FG1, F, 35)

a

Note: the profile of the participant who made the quote is indicated by means of country code (BE = Belgium, PT = Portugal, UK = United Kingdom), online identification number or focus group number (FG1$6)$, gender ( $F=$ female, $M=$ male) and age or age group (in years).

their preference for traditional (perceived as natural) meat simply because it is produced in a familiar, traditional way, both in terms of animal husbandry and meat processing. The artificial nature of cultured meat induced revulsion and discouraged the participants from being interested in consuming it (Box $1 \mathrm{~L}, \mathrm{M}$ ).

The participants' judgment of cultured meat as unnatural was to a certain extent an emotional reaction as it was closely linked to feelings of revulsion towards this novel product. Other researchers have suggested that in the context of food the term 'natural' often has an emotive appeal (Guerrero et al., 2010) and indeed it can be argued that 'natural' can evoke nostalgia and attachment to cooking traditions, 
Box 2

Connecting cultured meat with benefits and risks.

Envisaging few personal benefits

A "I doubt that the meat [will have] the flavor of a real chop or steak." (PT FG3, M, 50) ${ }^{\text {a }}$

B "A lot depends on how everything is commercialized. If it comes, I would definitely try it. But it should taste good and have proven benefits." (BE FG3, F, 24)

C "If it's tasty and if it tastes the same and it's the same, then, yeah, why not?!" (UK FG5, M, 35)

D "If it would be the same price, people wouldn't buy it. They might stay with their familiar products. If it's cheaper, I would buy it." (BE $F G 5, F, 33)$

E "I don't think so because I really like eating meat but just the thought of those animals getting slaughtered is painful. For me it doesn't have to be cheaper. If it would be the same price level, I would take it because no animals were killed." (BE FG5, F, 38)

Acknowledging potential societal benefits

F "If you don't need animals anymore and that's as good as the real stuff. And you eliminate that high ecological footprint. This could be interesting." (BE FG1, F, 35)

G "You could produce it where you eat it. This would decrease transport drastically and you could produce it everywhere. This could be an advantage." (BE FG5, M, 46)

$\mathrm{H}$ "If there aren't negative impacts in terms of health, this doesn't shock me, to fight off world hunger and to reduce costs, both in terms of economic costs and in terms of carbon footprint." (PT FG2, M, 43)

I "For example you have a synthetic steak and in Ethiopia there is massive starvation. If it is to survive, that's no problem. But if it is for a steak in a cosy restaurant ... There are a lot of factors one should think about when evaluating this." (BE FG1, M, 45)

$\mathrm{J}$ "But I mean, the ... the third world and stuff, I mean, that sort of ... that sort of research in ... you know, if you think about the amount of people that are starving in poor places like Africa, if you could generate a food source that was sustainable, you know, it could change the world for millions of people, couldn't it? So, that's why I'm open to the concept of them trying to develop something like this." (UK FG1, M, 40)

Fearing personal risks

$\mathrm{K}$ "I would have difficulty using this type of meat in my diet ... Even if it is well documented, it is still synthetic, and what is not natural always ends up revealing contraindications, even in the medium term." (PT Online318, F, 36-40)

L "How do we know that many years down the line they will not decide that synthetic meat harms you in some way? After all, after generations of eating red meat it is only in the last few years that we have heard so much about how detrimental to our health red meat is." (UK Online488, F, 41-50)

Worrying about potential adverse societal consequences

$\mathrm{M}$ “It has benefits in terms of greenhouse gas emissions, for instance, doesn't affect nature so much, but is it so if animals no longer exist? It also messes with the whole lifecycle. There needs to be pastures, animals, even manure, and if these no longer exist, it is quite scary." (PT FG4, F, 42)

$\mathrm{N}$ "I do not understand the advantage of synthetic meat. There will still be pasture and forest destruction and soil erosion. In addition, the synthetic red meat will continue to have the harmful nutrients. I do not get the benefits." (PT Online310, F, 25-30)

$\mathrm{O}$ "All the fields of the cows will have been built upon, won't they?! Industry, housing developments and ..." (UK, FG1, M, 40), and "... car parks, probably!" (UK FG1, M, 34)

a Note: the profile of the participant who made the quote is indicated by means of country code (BE = Belgium, PT $=$ Portugal, UK $=$ United Kingdom), online identification number or focus group number (FG1-6), gender ( $F=$ female, $M=$ male) and age or age group (in years).

identity, childhood memories, or the realm of home. In line with previous research, nature was constructed as something pure and not manipulated by humankind (Burri, 2009), which led the participants to consider cultured meat as something "abnormal" (Box 1N).

Idiomatic expressions such as "playing God" and "messing with nature" characterized the participants' reasoning around the lack of naturalness of cultured meat, and were invoked to reject the technology or to express doubts about its purported benefits, particularly in relation to nutritional value and health. Such reactions echo the findings of de Barcellos et al. (2010, p. 727), who found that consumers perceived novel beef technologies, e.g. shock wave treatment, as "messing with their food", and expressed preference for the less invasive (and more familiar) technologies such as freezing (Box 10, P).

To bolster their construction of cultured meat as unnatural and even as counter to human nature, the participants sometimes appealed to popular notions of science, i.e. that meat is an inherent part of the human diet and even of human evolution. However, the notion of evolution was not used only with respect to the past but also to the future, as illustrated in the excerpts in Box 1Q-S.

\subsection{Connecting cultured meat with benefits and risks}

This theme encapsulates how the participants engaged in connecting cultured meat with product attributes, and weighing up the potential expected benefits and risks of cultured meat, both in relation to themselves as individual consumers and to society as a whole.

\subsubsection{Envisaging few personal benefits}

Most participants did not express much interest in trying cultured meat, nor did they see it as a product with desirable attributes or as presenting benefits for their personal health or consumption practices, with some declaring off the record that they would not "feed it to [their] kids". However, there were some who expressed curiosity to taste cultured meat, and qualified their willingness to try it with the need of assurance of its wholesomeness in terms of health benefits or equivalence to traditional meat in terms of taste, texture, or cooking properties. Nevertheless, some positive connections were also made and formulated while acknowledging that the likelihood of ever having the chance to try cultured meat is anyhow very low (Box $2 \mathrm{~A}-\mathrm{C}$ ). 
Box 3

Further reflection on the application of science in society.

Perceiving uncertainty in scientific knowledge

A "They say that it is built through making use of animal cells, but who tells us that the DNA of these animals is not already infected and that by multiplying these cells the diseases will not continue to persist there?" (PT FG6, M, 33) ${ }^{\mathrm{a}}$

B "Can something produced in-vitro replace something produced naturally?" (PT Online315, M, 36-40)

C "How 'alive' are the cells involved in the production of synthetic meat?" (UK Online507, F, 18-24)

D "I find it really hard to have an opinion about this. Intuitively I am against this but if I were to think more about it ... it's really difficult. Is it good or bad? Do we know enough about it? You can do everything now with science and technology. Where is the limit?" (BE FG3, F, 24)

Demanding controllability and regulations

E "How long will it take before you know that it's real meat or not? Will they tell you? No, probably not. If they can get your money, I don't think you will never know what you will eat." (BE FG1, M, 49)

$\mathrm{F}$ "What if synthetic meat really gets a lot of control? And not only is put on the market to get profit!." (BE Online378, M, 50 +) "Unfortunately, I was unable to keep watching the video. However, as a consumer I would be concerned about the use of in-vitro meat, just as I am about the use of genetically modified crops. I would want to be certain that this sector was very tightly regulated and that if/once this is released for sale, I would wish to ensure that it was very clearly labeled and adequate information provided to consumers about this product and any way in which it had been modified." (UK Online494, M, 31-35)

Trusting science and accepting (inevitable) scientific progress

G "Techniques like stem cell research are becoming possible and could be useful techniques for many different problems." (BE FG3, M, 53)

$\mathrm{H}$ "If there are a lot of advantages also for the livestock, I wouldn't say no immediately to this scientific development." (BE FG3, F, 60)

I "But if you think about it, there are already a number of things where we have intervened with nature and where we got used to. For example, the fact that a chicken lays an egg every day, it's not like this in nature. Or a cow that keeps giving milk for years. We are doing this type of interventions already for a long time. And this is again another step forward. I have no idea what I would do if [synthetic meat] was in store." (BE FG3, M, 37)

$\mathrm{J}$ "Nothing surprises me anymore because a few years ago if they told to my grandfather or great-grandfather that it would be possible to grow massive amounts of fish through aquaculture, they would not believe it was ever possible." (PT FG5, M, 57)

$\mathrm{K}$ "The astronauts today also eat food from a tube, and they are in space for six months. If they can do such a thing, why can't we evolve in our eating behavior as well? It could be possible in the future that you take a tube to eat and you are ready for the day." (BE FG1, M, 49)

${ }^{\mathrm{a}}$ Note: the profile of the participant who made the quote is indicated by means of country code (BE = Belgium, $\mathrm{PT}=$ Portugal, $\mathrm{UK}=$ United Kingdom), online identification number or focus group number (FG1-6), gender ( $F=$ female, $M=$ male) and age or age group (in years).

It is worth noting that the Belgian participants were the most in favor of trying cultured meat, while the UK participants expressed the strongest opposition to this novel food. Among the Belgian participants, people attached different expected benefits to cultured meat, ranging from expected personal economical to ethical benefits (Box 2D, E).

Overall, the participants saw few direct personal benefits in cultured meat in terms of expected taste, improving their eating habits, or personal health. While a few people expressed willingness to try cultured meat (if not more expensive and mostly out of ethical considerations), most were against the idea of trying cultured meat and did not imagine consuming it if it ever became commercially available.

\subsubsection{Acknowledging potential societal benefits}

Some participants viewed cultured meat as bringing certain benefits to society, mainly environmental and ethical ones, such as the reduction of the carbon footprint of red meat production, or the elimination of suffering among farm animals (Box 2F, G). Others accepted that cultured meat might bring some benefits to the world by solving issues such as food shortages or food insecurity, but with the proviso that cultured meat should not pose a risk to human health (Box $2 \mathrm{H}$ ).

It is noteworthy that the benefits of cultured meat were envisaged not necessarily in the context of local everyday life, but were often rather imagined at a global level, such as reducing "world hunger" or helping "the children in Africa that are starving" (UK FG3, F, 25). References to developing economies or "poor places like Africa" and "the third world" were used not so much to highlight the potential direct benefits of cultured meat in this respect, but rather to identify the kind of consumers that would be presumably be more prepared to accept cultured meat out of pure necessity (Box 2I, J). Similarly, some British participants argued that "we don't need synthetic meat as a nation", however, "as a planet, possibly" given the nine billion people that are expected to inhabit it by 2050 . At the same time, many participants envisaged cultured meat to be consumed not in their own lifetime anymore, but rather by future generations in a distant and somewhat dystopian future.

\subsubsection{Fearing personal risks}

A number of concerns were expressed about the potential negative long-term effects of cultured meat on human health, which largely centered on what might represent the 'unknown' dimension of risk (cf. Slovic, Fischhoff, \& Lichtenstein, 1986). Concerns about potential unknown risks have often been attached to novel foods and technologies (Grunert et al., 2011; Ueland et al., 2012), and cultured meat was no exception (Box 2K).

When thinking about the potential long-term consequences of cultured meat, some participants extrapolated to genetically modified (GM) foods and animal cloning and thus invoked notions of being 'unnatural' and 'unknown'. Other participants drew analogies to red meat and argued that negative health effects can only become discernible after a certain number of years and through evidence-based scientific research (Box 2L).

As consumers, the participants' main concerns about cultured meat were in terms of expected poor nutritional value and unknown negative health impacts. Again, these perceptions of risk were underpinned by considerations of (un)naturalness as the participants argued that what is not natural is likely to have detrimental effects on human health. The participants insisted that convincing health and safety checks and quality controls would have to be carried out on cultured meat before marketing it.

\subsubsection{Worrying about potential adverse societal consequences}

The participants also expressed concerns about the kind of human society in which a futuristic, almost science-fictional product like cultured meat would be consumed, and the impact this would have on human societal organization. For example, in relation to human cultural practices like barbecues or Sunday roasts, the British participants cynically noted that in the future people would invite their families round for "a synthetic roast". While the participants could envisage societal and environmental benefits of cultured meat, they 
expressed concerns about the loss of farming traditions and agricultural jobs, and viewed cultured meat as "the end of a system", which was not really wanted (Box $2 \mathrm{M})$.

Some participants raised the issue of the amount of energy needed to stimulate muscle stem cells to grow and produce cultured meat on an industrial scale, and wondered what would be the environmental impact of this needed energy source. Similar environmental concerns were expressed in relation to potential loss of pasture lands, greenery and inevitable industrialization and urban sprawl (Box 2N, O).

\subsection{Further reflection on the application of science in society}

Largely, this master theme encapsulates the concerns that the participants expressed in relation to the scientific and regulatory aspects of cultured meat and its marketing to consumers. These will be discussed in turn in the sub-themes below.

\subsubsection{Perceiving uncertainty in scientific knowledge}

The participants were skeptical about how the science behind cultured meat might be applied safely and practically in food production, and drew attention to a number of aspects such as potential "mutations" occurring during the production process, or the presence of bacteria in the lab causing contamination of complete production batches. Generally, they struggled to make sense of how cultured meat can be brought into "massive production from a single cell" and wondered about how healthy animals would be selected for the initial cell harvesting (Box 3A). Quite a few questions were raised about how cultured meat is produced in the laboratory as people tried to make sense of the scientific process behind, and many participants expressed curiosity in this sense (Box 3B, C).

The production of cultured meat was viewed through the lens of more familiar practices such as vivisections, or more familiar risks like cell mutation and cancer. Comparisons were made to asbestos, which was believed to be safe until it was found to be carcinogenic, in a manner similar to the analogies drawn between nanotechnology and asbestos in past research (Burri, 2009). Overall, the participants were concerned about 'manufacturing defects' and many expressed disquiet at the notion of science being used to create cultured meat, as they believed that scientific progress should not push the boundaries of science and risk losing touch with normality (Box 3D).

\subsubsection{Demanding controllability and regulations}

The participants' concerns about science and technology also extended to issues of risk governance and control over the potential mismanagement of cultured meat production. They expressed concerns about the regulatory framework that would be necessary to oversee the production and marketing of cultured meat to consumers, and raised issues also about food safety tests, consumer choice, and transparency in the marketing strategy, such as honest information provision and proper labeling (Box 3E, F).

The participants reflected on the end purpose of cultured meat and its target consumers, and thus brought up issues of ethics: is cultured meat meant to relieve world hunger, or is it created as yet another novel food for mere profit of an industry? Interestingly, the participants' reactions to the notion of cultured meat did not necessarily rely on the information contained in the YouTube video shown, as some participants felt uneasy watching the video yet were able to express strong opinions about it, as illustrated in Box 3F. What this last quote also indicates is that stringent regulation, watertight guarantees and trustworthy labeling were requested in addition to information provision.

\subsubsection{Trusting science and accepting (inevitable) scientific progress}

Participants' concerns about the safety of the science behind cultured meat, and the need to have a transparent regulatory process were linked with an acknowledgement that scientific progress is inevitably part of human society and in turn with a more positive stance towards cultured meat (Box 3G, H).

Some participants expressed acceptance of the idea that cultured meat would have to be developed for environmental sustainability and that such changes would not be able to be resisted. Despite the perceptions of cultured meat as 'unnatural', the participants acknowledged that other human interventions and practices, for example, in agriculture, science, or medicine, are also deviations from 'natural' yet are widely accepted (Box 3I-K).

As the last quote in Box 3 illustrates, cultured meat was paradoxically constructed as both the undoing and the embodiment of human evolution: on one hand, it was seen as going against what has evolved as a naturally human diet, while on the other hand, it was seen as part and parcel of human scientific progress, technological innovation and an opportunity to survive in the future.

\section{Discussion}

\subsection{Disgust and perceived unnaturalness as initial reactions}

The present study provides empirical insights into consumers' reactions and attitude formation towards cultured meat. It is important to understand what consumers compare cultured meat to, to assess their initial reactions and components of their attitude formation, in addition to the analogies they draw (Marcu et al., 2014). These insights might tell about future consumer willingness to accept or not cultured meat and guide related food policy decisions, the further product development, marketing and communication strategies of those directly involved in its development as well as of those expecting or facing future competition from it.

Consumers' initial reactions when learning about cultured meat were underpinned by feelings of disgust (see also Pluhar, 2010) and considerations of unnaturalness (see also Hopkins and Dacey, 2008). Several studies (e.g. Grunert, 2005; Verbeke \& Vackier, 2004) have reported that the main markers of quality in meat for consumers are related to taste and the production process, in addition to health and convenience. The findings of this study confirm that as first impressions cultured meat was indeed assessed in terms of expected taste or sensory appeal (something consumers are most likely not willing to compromise on, e.g. Verbeke, 2006) and production process characteristics (away from a "natural" process). In line with previous research which has shown that consumers prefer beef that is "natural" and not touched by technological interventions that are perceived as "too invasive" (de Barcellos et al., 2010), our results suggest that cultured meat is likely to be rejected by traditional meat consumers at least as an initial reaction as long as it is perceived as being heavily processed, deviating from the socio-cultural norm of naturalness and not mimicking traditional meat in terms of sensory characteristics.

\subsection{Few personal but distant societal benefits}

Beyond initial reactions, which are typically driven by feelings and emotions when facing a concept or idea for the first time, consumers subsequently formed more concrete beliefs through considering product attributes and connecting these with possible benefits and risks. Whereas meat consumers envisaged few direct personal benefits from cultured meat, largely because of uncertainty about its taste and price, they were more open to perceiving possible global societal benefits from a partial shift to cultured instead of traditional meat.

It could be argued that by locating the potential benefits of cultured meat at the global and societal level, in the future and in distant places like "Africa" or "the third world", our Western consumers were able to distance themselves from it - accepting cultured meat in principle and as a product that is suitable to others but not necessarily beneficial to their personal, everyday consumption practices. This ambivalence 
over the personal versus societal benefits of cultured meat is in some ways reminiscent of NIMBY-ism ("Not In My Back Yard") (e.g. Burningham, Barnett \& Thrush, 2006), a psychosocial phenomenon which has been used to describe citizen quasi-simultaneous acceptance 'in principle' and rejection 'in practice' of novel technologies such as renewable energy (Barnett, Burningham, Walker \& Cass, 2012) or safety-improving interventions in the beef chain (de Barcellos et al., 2010).

\subsection{Personal and societal risks}

Perceived personal risks from eating cultured meat were largely underpinned by considerations of both unnaturalness and uncertainty. Participants feared nutritional deficiencies, unknown adverse health effects and long-term health consequences from eating cultured meat. This corresponds with Frewer et al. (2011) who concluded that those technologies characterized as having a bioactive component (which is the case with cultured meat) raise particular concerns among people. This is especially because of feared possible unpredictable effects, uncontrolled use and ethical concerns, often more so than because of perceptions of unnaturalness or unfamiliarity as such. As Grunert et al. (2011, p. 254) have pointed out, there are certain 'killers' of technology acceptance among consumers, namely: "unfamiliarity with the technology, the possible presence of uncertain or unknown risks, associations with making unacceptable products acceptable, and the perception of only industry benefits".

In addition, our study participants worried about adverse societal consequences associated with the loss of culinary traditions, rural livelihood, the preservation of livestock, open space and biodiversity. Cultured meat was thus perceived both as a material and a symbolic threat to human society, and the participants struggled to imagine a world where farm animals and the ecosystem they belong to no longer existed. Thus, cultured meat was not assessed only in terms of taste, price, and nutritional content, but also in terms of production process and the wider societal, environmental and economic conditions under which it would be manufactured and commercialized. In line with other research around new and emerging agro-food technologies, such as genetic modification and nanotechnology, this study indicates that cultured meat is characterized by 'epistemic uncertainty', i.e. a lack of 'stabilized scientific knowledge' (Burri, 2009) and that consumers respond to this uncertainty with perceptions of risk, particularly at the societal level, analogies to other risks, constructions of what is 'natural', and concerns over adverse long-term consequences of a shift from traditional to cultured meat production and consumption. For our participants, cultured meat seemed to open a Pandora's box of unknown societal, environmental, and technological evils.

\subsection{Weighing benefits versus risks}

Although a direct comparison of perceived benefits and risks is impossible based on the type of information collected, findings suggest that from the overall consumers' point of view, the potential personal and societal risks outweigh the expected benefits, especially considering that most of the benefits are believed to be situated at the global societal rather than at the personal or individual level, and therefore likely to be seen as less personally relevant or beneficial. Interestingly, the nature of the perceived risks was qualitatively different from that of the perceived benefits. While the benefits were constructed mostly in terms of concrete physical or tangible changes, e.g. cheaper food, reduction of $\mathrm{CO}_{2}$ emissions, and increased food production, the risks were seen not only in terms of physical changes (threats to human health) but also more intangible cultural changes. The participants seemed to be concerned in addition about the loss of traditional agricultural practices, the loss of cultural practices around meat consumption, and the potential changes in the symbolic values associated with human society, e.g. relationships with nature or with animals.
The participants associated cultured meat with visions of a dystopian futuristic society, such as those depicted in science-fiction films, and such associations attenuated perceived risks and led to doubts about cultured meat's potential nutritional or environmental benefits. In the wake of various public debates around the application of science and technology in the area of food, such as genetic modification, cloning, and nanotechnology, but also in the wake of food safety incidents such as residues, chemical contaminants or BSE (Bovine Spongiform Encephalopathy) in beef, consumers are wary of any novel technologies that seem to contain too much technological intervention with too little direct benefit for consumers.

\subsection{Deeper concerns and future challenges}

Further reflection on the application of this type of science in society revealed some deeper concerns about safety issues during the upscaling to industrial production of cultured meat, the need for regulation and proper labeling, but also some degree of curiosity about the feasibility and practicalities of producing cultured meat. It could be argued that when faced with the novelty of cultured meat, the participants reassessed what 'nature' means and what practices are truly 'natural', perhaps thus echoing the observation that 'nature' is nothing else than a socio-cultural construction typical of urban citizens (Burri, 2009). In a similar vein, Welin (2013) argued that a product like cultured meat may be perceived as 'natural' even if produced in an 'unnatural' way, and that products can be judged as good or bad regardless of their natural or unnatural status. In some cases, the participants' relative openness towards scientific innovation and progress, however, was not necessarily driven by their perceived benefits of cultured meat, but rather by a fatalistic feeling of being unable to resist the march of science and of human interventions in food and agriculture. Thus, while there were genuine perceptions of societal benefits such as solving world hunger, environmental problems or better controlling for the possible safety risks associated with red meat, the acceptance of cultured meat was also underpinned by defeatism in the face of scientific progress.

The results of this study support Blue's (2010, p. 148) assertion that food constitutes a significant context for exploring public engagement with science because "eating is an arena in which risk is negotiated". Indeed, our study participants engaged with the scientific aspects of cultured meat and tried to weigh up its potential benefits and risks. The participants understood cultured meat not only as a food but also as a scientific innovation, where science was pitted against 'nature', whereby 'nature' is largely a symbolic construction or a discursive tool that enables consumers to justify their rejection of novel technologies. It is likely that future consumer understanding of cultured meat will be underpinned by considerations of science and of what is 'natural', as studies on consumer reactions to agro-food technologies have often indicated (e.g. Frewer et al., 2011; Siegrist, 2008). As Whatmore (2002, p. 57) neatly puts it, "how does farming, the anchor of commonsense understandings of food production, fit into the creation of ovenready meals, genetically engineered plants and animals or synthetic food stuffs?". In the aftermath of public debates around genetically modified organisms (GMOs), particularly in the EU, and negative reactions against biotech companies, consumers are likely to see the creation (and potential future marketing) of cultured meat as being driven by corporate interests under the pretext of improving consumer health or protecting the environment (e.g. Marris, Wynne, Simmons, \& Weldon, 2001).

\subsection{Exploratory nature and timing of the study}

The coverage of three EU countries with a distinct profile, and the use of two complementary data collection methods (focus group discussions and online deliberations) to obtain consumer insight are strengths of the study. However, in according significance to the 
findings of this study it is important to bear in mind that it is qualitative and exploratory, and thus involving a relatively small number of participants. The fact that cultured meat was a hypothetical product to the study participants, and the selected video referring to 'synthetic meat' by necessity provided rather limited information, mostly alluding to the animal welfare debate facing traditional livestock production, formed the context for subsequent discussions. Nevertheless, the results of our study tie in with previous research on consumer acceptance of novel foods and technologies.

The data for this study were collected about one year before the unveiling of the first cultured hamburger to the public, yet the study participants were readily able to express emotional reactions and to form attitudes towards it and to link these to a range of considerations relating to science and regulation. Media coverage and consumer awareness were in their infancy when these data were collected, e.g. Goodwin and Shoulders (2013) had previously identified only 10 relevant articles dealing with cultured meat during the period 20052011 in EU newspapers. The general low awareness of cultured meat among consumers was confirmed in this study since none of our focus group and online participants were aware of this concept prior to the study. Thus, all participants were naïve consumers who were exposed to the concept for the first time during this study. Hence, cultured meat was for them a hypothetical product, something that may become a reality in some distant future. As a result, participants may have "placed less importance on the issue than they would if cultured meat was [at the time of the study] available", as noted also by Goodwin and Shoulders (2013, p. 449). Despite knowing little about the concept and despite the lack of media coverage or direct or even mediated experience with the product, people were easily able to discuss cultured meat and express a range of views.

After the subsequent public unveiling of the first cultured meat burger in August 2013, it is possible that consumers' opinions may have changed compared to those observed in our study. However, the translation of the technology into a real product may not be the only factor affecting opinion change, if any were to be observed. Seemingly unrelated events, such as the pan-European discovery of beef products adulterated with horse meat in 2013 , as well as other events in a person's life or social environment, may have affected consumers' attitudes towards meat products in general, and thus indirectly may have led to different reactions to cultured meat when this was firstly unveiled. Further studies are needed to establish whether the essence of consumer reactions after August 2013 is qualitatively different to those reactions observed in previous research.

\section{Conclusion}

This study provided insights about consumer reactions towards the concept of cultured meat in three EU countries. The analysis of the content of focus group discussions and online deliberations with meat consumers was structured along three master themes that reflect emotions and beliefs as components of consumers' attitude formation towards cultured meat. Consumers' initial reactions when learning about cultured meat were underpinned by feelings of disgust and considerations of unnaturalness. Consumers envisaged few direct personal benefits from cultured meat, but they acknowledged possible global societal benefits. Perceived personal risks from eating cultured meat were largely underpinned by considerations of unnaturalness and uncertainty, and therefore inducing some kind of fear of the unknown.

Consumer acceptance of cultured meat will ultimately depend on the product-related expectations and experienced performance. Besides perceptions about how cultured meat has been produced, once it becomes available and affordable for a broad segment the product will be evaluated in terms of attributes that provide consumers with relevant benefits and satisfaction. As with any food product, consumers will not be willing to compromise in terms of food safety and most likely also not willing to compromise much on taste or other attributes. By lack of product experience thus far, consumers form expectations based on the information received and based on image transfer from more familiar technologies and products. The positioning of cultured meat as an alternative, as a substitute or as a complement to conventional meat will play a crucial role because consumers are likely to refer to products with a similar positioning in the market.

Although cultured meat may contribute to solving major ethical concerns with respect to livestock production and animal slaughter for human consumption and may contribute to the alleviation of hunger problems in the world, insights from the present study indicate that public and consumer acceptance of the technology and the resulting end product cannot be taken for granted. In line with other research around new and emerging agro-food technologies, this study indicates that cultured meat is characterized by a lack of stabilized scientific knowledge and that consumers respond to this uncertainty with perceptions of risk, analogies to other risks, constructions of what they believe is natural, and concerns over adverse long-term consequences of a shift from traditional to cultured meat production and consumption.

\section{Conflict of interest}

The authors declare to have no conflict of interest.

\section{Acknowledgement}

This study is part of the FoodRisC project, which is funded under the Seventh Framework Programme (CORDIS FP7) of the European Commission; grant agreement no. 245124.

\section{Appendix A. Transcript of the YouTube video}

Meat is an excellent source of protein and quite tasty. But at what cost? The resources required to feed nine billion people meat are vast, even if it's just the wealthy ones. Many people are rejecting the cruelty of factory farming and practices like live animal export. And though they haven't been surveyed, it's likely the billions of primary providers, cows, sheep, pigs, fish and the rest are dead against it. ['You monster!' is flashed across the screen].

Could synthetic meat be the solution? It is meat, not tofu-based meat substitutes. And despite the name, not really synthetic. It's actual animal cells. Tissue engineers take a sample from a live adult animal and ideally that's all they have to endure. Then they grow the adult stem cells in vats of nutrient-rich broth, convert them to muscle cells, because meat is muscle, and grow them on a mono-biodegradable scaffold. The only hitch is muscle cells need exercise to survive and you can't run these ones around the paddock. You can stimulate them with tiny electrical impulses, but on an industrial scale it's prohibitively expensive. Research continues.

Thus far, the biggest cut contains millions of cells and is roughly the size of a contact lens. But when synthetic meat becomes a mainstream reality, will you eat lab-grown steak? And will knowing that no animals were harmed in the making of your burger change the way you relate to animals? [video ends with three questions displayed on the screen: What excites you? What frightens you? How might it change the way we live?].

Source: http://www.youtube.com/watch?v=iO9q_paCcWA.

\section{References}

Aston, L.M., Smith, J.N., \& Powles, J.W. (2012). Impact of a reduced red and processed meat dietary pattern on disease risks and greenhouse gas emissions in the UK: A modelling study. BMJ Open, 2(e00107), 1-9.

Austgulen, M.H. (2014). Environmentally sustainable meat consumption: An analysis of the Norwegian public debate. Journal of Consumer Policy, 37(1), 45-66.

Barnett, J., Burningham, K., Walker, G., \& Cass, N. (2012). Imagined publics and engagement around renewable energy technologies in the UK. Public Understanding of Science, 21(1), 36-50. 
Barnett, J., Fife-Schaw, C., Shepherd, R., Timotijevic, L., Fletcher, J., \& Fletcher, D. (2008) Online deliberative engagement: A pilot study. A report for the Wellcome Trust. London: The Wellcome Trust.

Batra, S.K., \& Kazmi, S.H.H. (2008). Consumer behaviour: Text and cases. New Delhi: Excel Books.

Blue, G. (2010). Food, publics, science. Public Understanding of Science, 19(2), 147-154.

Braun, V., \& Clarke, V. (2006). Using thematic analysis in psychology. Qualitative Research in Psychology, 3(2), 77-101.

Burningham, K., Barnett, J., \& Thrush, D. (2006). The limitations of the NIMBY concept for understanding public engagement with renewable energy technologies: A literature review. Working paper. Manchester: School of Environment and Development, University of Manchester.

Burri, R.V. (2009). Coping with uncertainty: Assessing nanotechnologies in a citizen panel in Switzerland. Public Understanding of Science, 18(5), 498-511.

de Barcellos, M.D., Kügler, J.O., Grunert, K.G., Van Wezemael, L., Péreze-Cueto, F.J.A. Ueland, O., \& Verbeke, W. (2010). European consumers' acceptance of beef processing technologies: A focus group study. Innovative Food Science and Emerging Technologies, 11, 721-732.

Flycatcher (2013). Kweekvlees [[Cultured meat]]. [2013-12-18] http://www. flycatcherpanel.nl/news/item/nwsA1697/media/images/Resultaten_onderzoek_ kweekvlees.pdf

Frewer, L.., Bergmann, K., Brennan, M., Lion, R., Meertens, R., Rowe, G., Siegrist, M., \& Vereijken, C. (2011). Consumer response to novel agri-food technologies: Implications for predicting consumer acceptance of emerging food technologies. Trends in Food Science \& Technology, 22, 422-456.

Goodwin, J.N., \& Shoulders, C.W. (2013). The future of meat: A qualitative analysis of cultured meat media coverage. Meat Science, 95, 445-450.

Grunert, K.G. (2005). Food quality and safety: Consumer perception and demand. European Review of Agricultural Economics, 32(3), 369-391.

Grunert, K.G., Verbeke, W., Kügler, J.O., Saeed, F., \& Scholderer, J. (2011). Use of consumer insight in the new product development process in the meat sector. Meat Science, 89(3), 251-258.

Guerrero, L., Claret, A., Verbeke, W., Enderli, G., Zakowska-Biemans, S., Vanhonacker, F., Issanchou, S., Sajdakowska, M., Granli, B.S., Scalvedi, L., Contel, M., \& Hersleth, M. (2010). Perception of traditional food products in six European regions using free word association. Food Quality and Preference, 21(2), 225-233.

Hocquette, J. -F., Mainsant, P., Daudin, J. -D., Cassar-Malek, I., Rémond, D., Doreau, M., Sans, P., Bauchart, D., Agabriel, J., Verbeke, W., \& Picard, B. (2013). La viande du future serat-elle produite in vitro? INRA Productions Animales, 26, 363-374.

Hocquette, J. -F., Van Wezemael, L., Chriki, S., Legrand, I., Verbeke, W., Farmer, L., Scollan, N.D., Polkinghorne, R., Rødbotten, R., Allen, P., \& Pethick, D.W. (2014). Modelling of beef sensory quality for a better prediction of palatability. Meat Science, 97, 316-322.

Hoek, A.C., Luning, P.A., Weijzen, P., Engels, W., Kok, F.J., \& de Graaf, C. (2011). Replacement of meat by meat substitutes. A survey on person- and product-related factors in consumer acceptance. Appetite, 56(3), 662-673.

Hopkins, P.D., \& Dacey, A. (2008). Vegetarian meat: Could technology save animals and satisfy meat eaters? Journal of Agricultural and Environmental Ethics, 21, 579-596.

Joffe, H., \& Yardley, L. (2004). Content and thematic analysis. In D.F. Marks, \& L. Yardley (Eds.), Research methods for clinical and health psychology (pp. 56-68). London: Sage.

Looy, H., Dunkel, F.V., \& Wood, J.R. (2014). How then shall we eat? Insect-eating attitudes and sustainable foodways. Agriculture and Human Values, 31(1), 131-141.

Marcu, A., Gaspar, R., Rutsaert, P., Seibt, B., Fletcher, D., Verbeke, W., \& Barnett, J. (2014s). Analogies, metaphors and wondering about the future: Lay sense-making around synthetic meat. Public Understanding of Science, http://dx.doi.org/10.1177 0963662514521106 (in press).

Marris, C., Wynne, B., Simmons, P., \& Weldon, P. (2001). Public perceptions of agricultural biotechnologies in Europe: Final report of the PABE research project. Lancaster: University of Lancaster.

Mattick, C.S., \& Allenby, B.R. (2012). Cultured meat: The systemic implications of an emerging technology. Proceedings of the IEEE International Symposium on Sustainable Systems and Technology. Boston: IEEE (May 2012).
McAfee, A.J., McSorley, E.M., Cuskelly, G.J., Moss, B.W., Wallace, J.M.W., Bonham, M.P., \& Fearon, A.M. (2010). Red meat consumption: An overview of the risks and benefits. Meat Science, 84(1), 1-13.

Morgan, D.L. (1996). Focus groups. Annual Review of Sociology, 22, 129-152.

Pan, A., Sun, Q., Bernstein, A.M., Schulze, M.B., Manson, J.E., Stampfer, M.J., Willett, W.C., \& Hu, F.B. (2012). Red meat consumption and mortality: Results from 2 prospective cohort studies. Archives of Internal Medicine, 172(7), 555-563.

Pluhar, E. (2010). Meat and morality: Alternatives to factory farming. Journal of Agricultural and Environmental Ethics, 23, 455-468.

Post, M.J. (2012). Cultured meat from stem cells: Challenges and prospects. Meat Science, 92, 297-301.

Post, M.J. (2014s). Cultured beef: Medical technology to produce food. Journal of the Science of Food and Agriculture, http://dx.doi.org/10.1002/jsfa.6474 (in press).

Rozin, P. (2005). The meaning of "natural": Process more important than content Psychological Science, 16(8), 652-658.

Schnall, S., Haidt, J., Clore, G.C., \& Jordan, A.H. (2008). Disgust as embodied moral judgment. Personality and Social Psychology Bulletin, 34, 1096-1109.

Siegrist, M. (2008). Factors influencing public acceptance of innovative food technologies and products. Trends in Food Science and Technology, 19, 603-608.

Slovic, P., Fischhoff, B., \& Lichtenstein, S. (1986). The psychometric study of risk. Risk Evaluation and Management, 1, 3-24.

Steinfeld, H., Gerber, P., Wassenaar, T., Castel, V., Rosales, M., \& de Haan, C. (2006) Livestock's long shadow - Environmental issues and options. Rome: Food and Agriculture Organization of the United Nations (FAO).

The Guardian (2013). Would you eat a synthetic beefburger? [2013-08-05] http://www. theguardian.com/commentisfree/poll/2013/aug/05/eat-synthetic-beefburger-poll

Ueland, O., Gunnlaugsdottir, H., Holm, F., Kalogeras, N., Leino, O., Luteijn, J.M., Magnusson, S.H., Odekerken, G., Pohjola, M.V., Tijhuis, M.J., Tuomisto, J.T., White, B.C., \& Verhagen, H. (2012). Stage of the art in benefit-risk analysis: Consumer perception. Food and Chemical Toxicology, 50(1), 67-76.

Vanhonacker, F., Van Loo, E.J., Gellynck, X., \& Verbeke, W. (2013). Flemish consumer attitudes towards more sustainable food choices. Appetite, 62, 7-16.

Verbeke, W. (2006). Functional foods: Consumer willingness to compromise on taste for health? Food Quality and Preference, 17, 126-131.

Verbeke, W. (2011). Consumer attitudes and communication challenges for agro-food technologies. Agro-Food Industry Hi-Technology, 22, 34-36.

Verbeke, W. (2015). Profiling consumers who are ready to adopt insects as a meat substitute in a Western society. Food Quality and Preference, 39, 147-155.

Verbeke, W., Pérez-Cueto, F.J.A., de Barcellos, M.D., Krystallis, A., \& Grunert, K.G. (2010) European citizen and consumer attitudes and preferences regarding beef and pork. Meat Science, 84, 284-292.

Verbeke, W., Sans, P., \& Van Loo, E. J. (2015). Challenges and prospects for consumer acceptance of cultured meat. Journal of Integrative Agriculture, 84, http://dx.doi.org/10. 1016/S2095-3119(14)60884-4 (in press).

Verbeke, W., \& Vackier, I. (2004). Profile and effects of consumer involvement in fresh meat. Meat Science, 67, 159-168.

Verbeke, W., Van Wezemael, L., de Barcellos, M.D., Kügler, J.O., Hocquette, J. -F., Ueland, Ø., \& Grunert, K.G. (2010). European beef consumers' interest in a beef eating-quality guarantee. Insights from a qualitative study in four EU countries. Appetite, 54, 289-296.

Welin, S. (2013). Introducing the new meat. Problems and prospects. Etikk i Praksis Nordic Journal of Applied Ethics, 7, 24-37.

Whatmore, S. (2002). From farming to agribusiness: The global agrofood system. In R.J. Johnson, P.J. Taylor, \& M.J. Watts (Eds.), Geographies of global change (pp. 57-67). Oxford: Blackwell.

Zajonc, R.B. (1980). Feeling and thinking - Preferences need no inferences. American Psychologist, 35, 151-175. 